\title{
A SIMULAÇÃO NO ENSINO DE ENFERMAGEM: REFLEXÓES E JUSTIFICATIVAS A LUZ DA BIOÉTICA E DOS DIREITOS HUMANOS
}

\author{
Raphael Raniere de Oliveira Costaํㅜㄹ Soraya Maria de Medeiros², José Carlos Amado Martins ${ }^{3}$, Veró- \\ nica Rita Dias Coutinho ${ }^{3}$
}

Resumo: Objetiva-se refletir sobre a simulaçáo no ensino de enfermagem a luz da bioética e dos direitos humanos. Trata-se de ensaio reflexivo que parte da premissa que o contexto formativo atual em saúde e enfermagem deve contemplar, em seus processos, estratégias de ensino e aprendizagem que levem em consideração as diversas questóes éticas e bioéticas, dos direitos humanos, dos avanços tecnológicos e do conhecimento científico. Justifica-se o uso da simulação no ensino de enfermagem a partir da perspectiva da dignidade da pessoa humana, da não instrumentalização da pessoa humana, da igualdade, e da não discriminação. Além disso, são apontados alguns princípios fundamentais da bioética e sua relação com a simulação. Discute-se ainda, as contribuiçóes dessa estratégia de ensino e aprendizagem na perspectiva do doente/usuário, do estudante, da universidade, e das instituições de saúde. Ao considerar esses aspectos, é imprescindível pensar numa prática formativa que incorpore essas dimensóes nos seus processos de formação dos futuros enfermeiros.

Palavras-chave: ética, bioética, simulação, ensino de enfermagem

La simulación en la enseñanza de enfermería: reflexiones y justificaciones a la luz de la bioética y de los derechos humanos

Resumen: El objetivo es reflexionar sobre la simulación en la enseñanza de enfermería a la luz de la bioética y de los derechos humanos. Se trata de un ensayo reflexivo que parte de la premisa que el contexto formativo actual en salud y enfermería debe contemplar en sus procesos estrategias de enseńanza y aprendizaje que tengan en cuenta las diversas cuestiones éticas y bioéticas de los derechos humanos, de los avances tecnológicos y del conocimiento científico. Se justifica el uso de la simulación en la enseńanza de enfermería desde la perspectiva de la dignidad de la persona humana, de la no instrumentalización de la persona humana, de la igualdad y de la no discriminación. Además, se señalan algunos principios fundamentales de la bioética y su relación con la simulación. Se discute además las contribuciones de esta estrategia de enseñanza y aprendizaje en la perspectiva del paciente / usuario, del estudiante, de la universidad y de las instituciones de salud. Al considerar estos aspectos, es imprescindible pensar en una práctica formativa que incorpore esas dimensiones en sus procesos de formación de los futuros enfermeros.

Palabras clave: ética, bioética, simulación, enseñanza de enfermería

\section{Simulation in training nurses: reflections and justifications based on bioethics and human rights approaches}

Abstract: The aim of this paper is to reflect about the use of simulation in training nurses based on bioethics and human rights approaches. This is a reflexive essay based on the assumption that the current training context in health and nursing must include in the process teaching and learning strategies which take into account diverse ethical and bioethical questions about human rights, technological development and scientific knowledge. The use of simulation in training nurses is justified on human dignity, not in the instrumentalization of the person, equity and not discrimination. Furthermore, some fundamental principles of bioethics and their relation to simulation are pointed out. Moreover, the contributions of this teaching and learning strategy are discussed under the perspectives of patient/user, student, university and health care institution. Considering these issues, it is essential to plan a training practice incorporating these dimensions in the training process of future nurses.

Key words: ethics, bioethics, simulation, nursing training

\footnotetext{
${ }^{1}$ Universidade Federal do Rio Grande do Norte, Natal/RN, Brasil Correspondência: raphaelraniere@hotmail.com

2 Departamento de Enfermagem da Universidade Federal do Rio Grande do Norte, Natal/RN, Brasil

${ }^{3}$ Escola Superior de Enfermagem de Coimbra, Coimbra, Portugal
} 


\section{Introdução}

Parte-se da premissa que o contexto formativo atual em saúde e enfermagem deve contemplar, em seus processos, estratégias de ensino e aprendizagem que levem em consideração as diversas questôes éticas e bioéticas, dos direitos humanos, da segurança do paciente, dos avanços tecnológicos e do conhecimento que tem sido produzido e divulgado.

Tem-se hoje disponíveis equipamentos tecnológicos e tecnologias educacionais que se traduzem como um substancial ao desenvolvimento de competências e habilidades no contexto da formação em saúde e enfermagem. As instituiçóes formadoras têm incorporado em seus laboratórios dispositivos que possibilitam ao estudante vivências prévias de situaçóes pertinentes aos futuros contextos de trabalho no mundo atual do trabalho em saúde.

Hoje, é indispensável considerar a utilização de equipamentos como manequins e simuladores, dentre outras tecnologias, no processo de formação de profissionais de saúde. Pois, aprender e praticar técnicas e ou procedimentos em pacientes em situaçáo de vulnerabilidade passa a ser uma estratégia primitiva, inadequada e eticamente injustificável, sempre que o treino prévio for possível no contexto simulado.

A minimização dos erros em saúde e enfermagem, a garantia da segurança do paciente, a busca pela melhoria do estado de saúde do paciente/usuário, o respeito pela condição e ou situação de saúde do indivíduo, além da busca por um atendimento integral e humanizado, são algumas das garantias e princípios que devem ser vislumbrados durante o processo formativo de profissionais da saúde e de enfermagem: tanto pelo órgão formador e seus representantes quanto pelos estudantes partícipes desse processo. Nesse cenário, é válido considerar também o papel das instituiçóes prestadoras de serviços para a saúde na garantia de processos que permitam a cultura da segurança e da atualização/ capacitação dos sujeitos partícipes da força de trabalho.

No que se refere ao processo de formação em enfermagem, a simulação é apontada como uma es- tratégia pedagógica favorável ao desenvolvimento de uma postura ética assim como a aplicação de seus princípios na prática clínica(1). Além disso, entre os estudantes de enfermagem, irá contribuir para que estes se desenvolvam eticamente a partir do reforço ao respeito aos seres humanos e a sua dignidade(2).

Ao considerar a relevância das discussóes sobre as implicaçóes éticas da escolha e uso de materiais e métodos no processo formativo em saúde e enfermagem, o estudo teve por objetivo refletir sobre a simulação enquanto estratégia de ensino e aprendizagem, a luz da bioética e dos direitos humanos.

De modo a organizar as premissas defendidas pelos autores, as reflexóes tecidas foram organizadas nos seguintes tópicos de discussão: "A simulação realística como estratégia educativa efetiva no ensino de enfermagem", "princípios relevantes em matéria de direitos humanos", "princípios relevantes em matéria de bioética", e "justificativas éticas para a utilização da simulação no ensino de enfermagem".

\section{A simulação realística como estratégia educati- va efetiva no ensino de enfermagem}

A simulação no ensino de enfermagem é identificada como uma técnica de ensino que se utiliza de tecnologias para reproduzir cenários que simulam a prática, em ambiente controlado e realista, onde o estudante participa ativamente do processo de ensino e aprendizagem, com a finalidade de praticar exaustivamente, aprender, refletir e avaliar produtos e processos.

Nessa perspectiva, o uso da simulaçáo no ensino de enfermagem vem ganhando força em todo o mundo. Os estudos têm mostrado experiências a partir do uso da simulação em diferentes contextos de ensino e aprendizagem e com diversas finalidades(3).

Além disso, há evidências que a simulação gera diversas competências e habilidades relevantes para o exercício profissional do enfermeiro como a tomada de decisão, a empatia com a profissão, a articulação entre teoria e prática e entre outras (4-7). Estudo também mostra a contribuição da simulação para o desenvolvimento de liderança e me- 
lhoria nos processos dos serviços de saúde com consequente diminuição dos erros(8).

Ao reconhecer as contribuições da simulação no contexto da formação e educação em saúde e enfermagem, a Organização Mundial de Saúde (OMS) recomenda, que profissionais de saúde e Instituições de educação e formação devem usar simulaçáo na educaçáo dos seus estudantes e no treino(9). Destaca-se também a relevância de cooperação internacional para o desenvolvimento de novos estudos em diversas áreas de conhecimento em enfermagem(10).

\section{Princípios relevantes em matéria de direitos humanos}

Embora se reconheça as contribuiçóes da simulação no contexto da formação do profissional de enfermagem, é imprescindível destacar os aspectos éticos e algumas dimensóes em matéria de direitos humanos que se relacionam com a temática. A dignidade da pessoa humana, a não instrumentalização da pessoa humana, a igualdade, e a não discriminação, são alguns aspectos que merecem destaque discursivo.

Do ponto de vista da dignidade humana, o ser humano tem o direito de receber tratamentos, respeito e proteçáo independente de origem, raça, cor, credo e ou outra variável social e econômica. Este aspecto deve ser essencialmente trabalhado do modo transversal no ensino de enfermagem e, sobretudo, em simulaçôes. Na medida em que se planeja um cenário de simulação, é relevante que se enalteça esse aspecto. Portanto, a observaçáo do comportamento dos futuros enfermeiros, diante dos seus doentes/usuários, é um aspecto fundamental nesse processo de formação profissional e na consolidação do princípio natural da dignidade humana.

Com certa frequência, principalmente nos hospitais-escola, é comum encontrar estudantes realizando procedimentos em doentes que antes não fora praticado e ou repetido em outras oportunidades. Estudantes, muitas vezes imaturos e despreparados, não querem perder a oportunidade de realizar certos procedimentos. Por outro lado, tutores "comprometidos" querem que seus estudantes saiam do ambiente de aprendizagem com o maior número de vivências e técnicas realizadas. E o doente/usuário, que escolha tem?

Tão quão comum é se deparar com verdadeiras palestras de esclarecimentos de condutas e comportamentos após a realização de técnicas, por parte dos tutores, em frente ao doente/usuário em seus leitos. Esses eventos fazem do doente/usuário um sujeito-objeto. Descaracteriza-se o ser e sua autonomia e o faz instrumento. Portanto, encontra-se na simulação a possibilidade de oportunizar diferentes momentos de ensino e aprendizagem a partir do uso de tecnologias. Ainda assim, se faz necessário repensar a organização das práticas com contato direto com doentes e usuários e as maneiras de contornar situaçóes semelhantes as anteriormente descritas.

Igualdade e não descriminação caminham juntos. O profissional da enfermagem deve ser capaz de conhecer e reconhecer as dinâmicas das relaçóes de poder entre profissionais de saúde e usuários a partir da compreensão dos limites técnicos e científicos. Nessa perspectiva, as simulaçóes interprofissionais são possibilidades de contemplar esses aspectos. Para além da perspectiva técnica e científica, se faz necessário simular situaçóes que levem em consideração o princípio da equidade. Deve-se estimular os estudantes a refletir acerca de cenários que emergem de conflitos e dilemas éticos, na perspectiva de busca de estratégias de abordagens que contemplem os direitos humanos de todos os envolvidos no processo.

\section{Princípios relevantes em matéria de bioética}

A bioética é a forma da ética aplicada que diz respeito aos principais conflitos que surgem em contextos práticos que envolvem a ordem do mundo vivido e as tentativas de aperceber-se dele $(11,12)$. Nessa perspectiva, são apontados alguns princípios fundamentais: justiça, autonomia, beneficência e não maleficência. Ao considerar a simulação realística como técnica/estratégia de ensino e aprendizagem, suas etapas, abrangência, e possibilidades, é possível realizar um exercício de aproximação dos princípios da bioética com a estratégia anteriormente referida.

Segurança e justiça são valores que possuem uma ligação forte. São pressupostos de intervençôes 
em saúde adequadas. Intervençóes adequadas desembocam e pontuam fortemente a questão da segurança do paciente. Assim, a partir da simulação, podem-se trabalhar diversos aspectos que contribuem para a minimização de erros que venham a causar danos aos pacientes/usuários(13).

Durante a graduação em enfermagem, e a partir do uso da simulação, os estudantes têm a possibilidade de treinar exaustivamente procedimentos invasivos em simuladores que permitem experimentar a sensação do real. Sondagens, cateterismos, punçóes, auscultas, manobras de ressuscitação, comunicação e trabalho em equipe são algumas das possibilidades que a simulaçấo e os simuladores podem oferecer. Além disso, as reflexôes dos estudantes e do tutor/facilitador auxiliam no aprendizado.

Para além dos procedimentos invasivos, estudantes de enfermagem e enfermeiros podem vivenciar cenários com objetivos que superam a perspectiva do treinamento puramente técnico e possam adquirir outras competências e habilidades como a comunicação efetiva, a humanização, o trabalho em equipe, a gestão do cuidado, entre outras.

O princípio da autonomia refere-se tanto ao paciente/cliente quanto ao estudante. É fundamental que o estudante respeite a autonomia do paciente, no consentimento ou não para a realização de procedimentos e também no conhecimento sobre a aptidão do estudante na realização de técnicas e ou procedimentos. No que se refere à autonomia do estudante, é relevante considerar a sua disposição e necessidades de aprendizagem(13). Há que se considerar aqui a relevância da simulação realística como facilitador de processos ensino-aprendizagem mais participativos, envolvendo metodologias ativas que favorecem os aspectos cognitivos e o treino de habilidades psicomotoras. Nesse sentido, ressalta-se ainda o direito de desenvolvimento das potencialidades humanas, ou seja, direito de aprender do estudante, em condiçóes dialógicas que respeitem a sua autonomia e sua condição de sujeito do seu processo de conhecimento.

Não é difícil encontrar situaçóes em que os doentes/clientes se recusam a receber cuidados prestados por estudantes de enfermagem. A condição de saúde, o ambiente, as experiências em outras situações semelhantes e até mesmo a confiança no aprendiz são variáveis que podem influenciar nessa decisão. O estudante precisa compreender essas situaçóes e respeitar a decisão. Por outro lado, é indispensável que o estudante vivencie situações que farão parte dos seus futuros contextos de prática profissional. Dessa forma, simular situações que são relevantes e que nem sempre são encontradas nos estágios em serviços de saúde se faz necessário.

Outro aspecto que merece destaque é que a instituição formadora precisa considerar a aptidão do estudante e suas preferências para aprender. Há estudantes que gostam mais de exposição dialogada, outros de recursos audiovisuais, alguns que preferem formas mais interativas e a utilização de tecnologias digitais. Assim, a diversificação de estratégias de ensino e aprendizagem deve ser vislumbrada como alternativa.

A simulação realística, quando estruturada e inserida em um contexto curricular, precede outras estratégias e etapas da relação ensinar/aprender. Uma exposiçáo dialogada pode ser relevante antes do treino de habilidades, e, após esse treino, uma seção de simulação. Nessa perspectiva, diversificam-se os recursos materiais e as formas de compartilhar o conhecimento.

No que se refere ao princípio da beneficência e sua relação com a simulação, há que se considerar a obrigação moral de agir para beneficiar os usuários. A escolha pela propedêutica adequada, o uso de serviços que levem em consideração o atendimento integral do doente/usuário, dentre outros aspectos, deve ser levado em consideração ao se prestar cuidados. A partir da simulação, podemse treinar procedimentos, rotinas, entendimentos de fluxos e condutas(13).

Por fim, a não maleficência relaciona-se ao não infligir danos ao paciente/usuário. A minoração de erros pode evitar danos de todas as ordens: física, emocional ou financeira. Isso precede uma formação que permite o desenvolvimento da prática profissional com competência. $\mathrm{O}$ desenvolvimento de competências perpassa a diversificação de diferentes estratégias educacionais, como a simulação realística(13). 
O próprio processo de formação utilizando simulação permite nivelar a proficiência dos formandos, garantindo que esta não dependa apenas da casuística encontrada nas experiências clínicas. E assim, os resultados para o paciente não ficam a depender da "sorte" de se cruzar com um estudante mais ou menos experiente que o paciente do lado. Ou seja, torna-se o sistema mais justo para estudantes e pacientes.

$\mathrm{Na}$ medida em que, os órgãos formadores investirem em processos de formaçáo utilizando-se estratégias aprendizagem com o reforço da simulação realística, esses futuros profissionais também terão a beneficência do compromisso ético da instituição de responsabilizar-se por um ensino com o melhor nível de qualidade, contribuindo para a sua autonomia e competência dos enfermeiros.

Destaca-se ainda a não maleficência para o futuro profissional, como trabalhador, que em seus processos de trabalho corre riscos e agravos a sua saúde no exercício cotidiano de sua prática, uma vez que, tendo maior segurança e autonomia na sua prática, haverá menores possibilidades de ocorrência de erros envolvendo os pacientes/ usuários, com impacto negativo para os próprios trabalhadores, a instituiçáo o paciente/usuário e sua família.

\section{Justificativas éticas para a utilização da simu- laçáo no ensino de enfermagem}

O contato com pacientes/usuários durante a formação e atuação profissional de enfermeiros é, sem dúvidas, indispensável. Para tanto, é preciso considerar a necessidade de uma formação sólida e que permita que esse contato seja potencialmente benéfico. A partir dessa consideração, é relevante discutir as contribuições da utilização da simulação da simulação no ensino de enfermagem na perspectiva do doente/usuário, do estudante, da universidade, e das instituiçóes de saúde.

$\mathrm{Na}$ perspectiva do doente/usuário, ser atendido e ter suas necessidades de saúde ajustadas a partir de um profissional da enfermagem implica em ter princípios éticos e de direitos humanos garantidos. Acredita-se que um enfermeiro comprometido com questôes técnicas e éticas provém de uma formação mais sólida e complexa.
Para que essa formação seja favorecida, no ensino de enfermagem, a diversificação de técnicas/estratégias de ensino e aprendizagem deve se fazer presente nos currículos. Ao considerar as diferentes preferências e formas de aprender, o docente deve oportunizar ferramentas que facilitem o aprendizado. A simulação se insere nesse universo de oportunidades, se propóe a reproduzir situaçóes que comumente são encontrados na prática real e também aquelas que, frequentemente, o estudante não tem a oportunidade de vivenciar em alguns momentos da sua formação.

Um ambiente controlado e realista permite ao estudante vivenciar espaços, situaçóes, e treinar técnicas e ou procedimentos, dando-lhes oportunidade de errar e aprender com os erros, sem que esses erros tragam prejuízos à saúde de indivíduos. A possibilidade de repetir, vivenciar e experimentar as situações simuladas, quantas vezes forem necessárias, permite ao estudante aprender, refletir e também avaliar seu desempenho, postura e atitudes diante do vivido.

Além disso, a participação ativa dos estudantes no processo de aprendizagem projeta nestes a criação de uma postura autônoma, e o estabelecimento de uma relação horizontal com os demais sujeitos envolvidos nesse processo.

Ao considerar a competitividade do mercado de trabalho, as exigências éticas e legais, as competências e habilidades, e o perfil de egresso, as escolas de enfermagem têm efetuado grandes investimentos em laboratórios. É inaceitável que os estudantes de enfermagem aprendam e ou treinem procedimentos, num primeiro momento, em sujeitos acometidos por alguma desordem de saúde(14).

Sem dúvidas, o uso de tecnologias de ponta, como simuladores de alta fidelidade e equipamentos dispendiosos, tem feito parte da estrutura dos grandes centros e laboratórios de simulação realística. Porém, é válido considerar que, a depender do objetivo, esses equipamentos são relevantes, porém não determinantes ao escolher a simulação como estratégia/técnica de ensino e aprendizagem na aquisição de algumas competências e habilidades. 
Aprender em pacientes/usuários, embora pareça ser uma estratégia primitiva, ainda faz parte do contexto de algumas instituiçóes que formam enfermeiros. Normalmente, os estudantes são inseridos num contexto curricular que não dá espaço para que estes possam frequentar os laboratórios com maior frequência e treinar exaustivamente técnicas e procedimentos pertinentes à profissão. Além disso, o "conteudismo" ainda prevalece em alguns cenários formativos.

$\mathrm{Na}$ realidade brasileira, em algumas situações, os estudantes são inseridos em sequencias de aulas expositivas e demonstraçóes práticas, em seguida são convocados a participar de aulas práticas, que nem sempre são realizadas somente em laboratórios. Pode-se ainda encontrar escolas que inserem os seus estudantes diretamente nos cenários dos serviços de saúde para que estes pratiquem, sem uma sequência de repetições prévias, em pacientes/usuários.

Por outro lado, constata-se também a estruturação de escolas de enfermagem comprometidas com a formaçáo desses futuros enfermeiros. A reestruturação de currículos, a aquisição de infraestrutura laboratorial sofisticada e o investimento na contrataçáo de corpo docente qualificado, dentre outras medidas, também se faz presente.

No Brasil, atualmente, observa-se a disposição de um grande número de vagas autorizadas para abertura de instituiçóes e acesso aos cursos de graduação em Enfermagem pelo Ministério da Educação e Cultura (MEC) - entidade responsável pela regulamentação do ensino no Brasil. Além disso, a flexibilização das Diretrizes Curriculares Nacionais da Graduação em Enfermagem permite uma ampla formatação de modelos e estruturas na formação de novos enfermeiros. Diante dessa realidade, há que se inspecionar com certa prudência e cuidado a forma que essas ofertas têm sido viabilizadas.

O imediatismo dessa expansão pode não ser favorável à saúde. Processos formativos falhos podem comprometer a saúde de indivíduos e populações. A instalação de uma estrutura escolar inadequada pode culminar em uma formação fragilizada. Além disso, essa formação deficitária pode comprometer e ferir os princípios da bioética ao inse- rir o estudante que vivenciou falhas no seu processo formativo em ambientes que estes precisem pôr em prática aquilo que aprendeu e ou deveria ter aprendido.

A expectativa de lidar com pacientes/usuários parece tomar conta dos estudantes de enfermagem, principalmente nas séries iniciais. $\mathrm{O}$ acadêmico só se sente "estudante de enfermagem" quando é inserido em um serviço de saúde lotado de enfermos e repleto de procedimentos e ou técnicas a serem executadas. Essa expectativa, somada a deficiência de estruturas laboratoriais de algumas instituiçóes, e a concepção falha de que só se aprende fazendo - em doentes/usuários - permite uma antecipação de etapas/sequencias do processo. É, principalmente, nesse momento que os erros acontecem durante a graduação.

A partir da interpretação da pirâmide de Miller, pode-se identificar de que modo essas falhas acontecem, a partir do entendimento da relevância dos métodos de construção do conhecimento. Composta por quatro níveis, a pirâmide parte de uma base, o "sabe", para os outros níveis: "sabe como", "mostra como" e o "faz"(15). Nessa perspectiva, quando o currículo é dotado de sequências de ensinar e aprender, contemplando-se apenas a exposiçáo/disposiçáo de conteúdos e a inserção dos estudantes nos campos de práticas, o "saber como" e o "mostra como" passam a ser negligenciados.

No que se refere ao uso da simulaçáo nos serviços de saúde, muitos serviços têm optado por utilizar a simulaçáo para treinamento de condutas e fluxos. No Brasil, os Serviços de Atendimento Móvel de Urgência (SAMU), a Força Nacional e outras entidades têm apostado na simulação como estratégia de capacitação da sua força de trabalho. Além disso, em diversos países do mundo, a capacitação de equipes internas de urgências e emergências tem sido realizada a partir do uso da simulação. Neste sentido, a simulação apresenta-se como uma importante ferramenta nos processos de educação permanente e continuada em saúde.

\section{Consideraçóes finais}

Ao considerar as características do mundo atual e o mercado de trabalho, é imprescindível que as instituiçóes formadoras invistam em melhores es- 
truturas e recursos humanos a fim de favorecer uma formação mais próxima das necessidades exigidas pela sociedade. Além disso, a diversificação de estratégias e sequências de ensino e aprendizagem deve ser um elemento fundamental dentro da organização curricular na formação de enfermeiros.

O contato entre estudantes, profissionais e doentes/usuários deve ser mediado a partir do conhecimento, competências e habilidades, de modo que o produto dessa interaçáo tenha como estrutura e orientaçáo os princípios da bioética e dos direitos humanos. Ao considerar a complexidade dos processos formativos e a abrangência da simulação enquanto técnica de ensino, sua aplicabilidade perpassa as interfaces do doente/usuário, do estudante, da universidade, e das instituiçóes de saúde. Nesse sentido, justifica-se e encoraja-se a sua utilizaçâo no ensino de enfermagem.
A partir das reflexóes aqui tecidas, reconhece-se a simulação como uma técnica/estratégia de ensino e aprendizagem potencialmente transformadora no contexto formativo em enfermagem. Ao considerar a ética, a bioética, os avanços tecnológicos e o conhecimento científico é imprescindível pensar numa prática formativa que incorpore essas dimensóes no $s$ seus processos de formação dos futuros enfermeiros.

Entretanto, percebe-se a carência de estudos, tanto a nível nacional quanto internacional, sobre a temática. Sugere-se o desenvolvimento de investigaçóes acerca da contribuição efetiva da estratégia da simulação no que se refere a proteção e garantia dos direitos humanos e dos princípios da ética e bioética. Investigaçóes que objetivem a observação da inserção dos estudantes de enfermagem e da área da saúde - que foram formados com experiências em simulaçôes - no que se refere as suas práticas, as atitudes, e competências e habilidades parecem ser fundamentais para que se amplie o conhecimento nessa temática táo peculiar e complexa. 
A simulação no ensino de enfermagem - Raphael Raniere de Oliveira Costa et al.

\section{Referências}

1. Martins JCA. Learning and development in simulated practice environments. Revista de Enfermagem Referência 2017; 4(12): 155-162. https://doi.org/10.12707/RIV16074

2. Buxton M, Phillippi J, Collins M. Simulation: A new approach to teaching ethics. Journal of Midwifery \& Women's Health 2014; 60(1), 70-74. Available from: https://www.ncbi.nlm.nih.gov/pubmed/25141791

3. Costa RRO, et al. Tipos e finalidades da simulação no ensino de graduação em enfermagem: revisão integrativa da literatura. Revista Baiana de Enfermagem 2016; 30(3): 1-11. http://dx.doi.org/10.18471/rbe.v30i3.16589

4. Kelly SH. Evaluation methods used in simulation: a survey of faculty and student perceptions in an undergraduate nursing programa [tese de doutorado]. Pittsburgh (PA): School of Education the University of Pittsburgh; 2014.

5. McEwan B, Hercelinskyj G. An internal audit of a virtual learning space to facilitate clinical decision-making in nursing. Collect Essays Learn Teach 2012; 5: 132-136. Available from: http://files.eric.ed.gov/fulltext/EJ1058795.pdf

6. Botma Y. Nursing student's perceptions on how immersive simulation promotes theory-practice integration. IJANS 2014; 1:1-5. https://doi.org/10.1016/j.ijans.2014.04.001

7. Oliveira SN, et al. A pedagogia por trás da experiência clínica simulada: uma percepção de estudantes de enfermagem. Revista Iberoamericana de educación e investigación em enfermeria 2015; 5(3): 56-63. Available from: http://www.enfermeria21.com/revistas/aladefe/articulo/173/

8. Shapira-Lishchinsky O. Simulations in nursing practice: toward authentic leadership. J Nurs Manag 2014; 22(1):60-9. https://doi.org/10.1111/j.1365-2834.2012.01426.x

9. World Health Organization. Interprofessional collaborative practice in primary health care: nursing and midwifery perspectives: six case studies. [Internet]. Human Resources for Health Observer, 13. Geneva; 2013. Available from: URL: http://www.who.int/hrh/resources/IPE_SixCaseStudies.pdf

10. Cassiani SHB, et al. The situation of nursing education in Latin America and the Caribbean towards universal health. Rev. Latino-Am. Enfermagem 2017; 25: e2913. http://dx.doi.org/10.1590/1518-8345.2232.2913

11. Schramm FR. Toda ética é, antes, uma bioética. Humanidades 1994; 9(4): 324-331.

12. Schramm FR. A bioética no Brasil entre o antigo e o novo. Cad Adenauer 2002; 3(1): 87-101.

13. Decker S. Simulation and Ethics. In: Jeffries P. Simulation in Nursing Education: from conceptualization to evaluation. New York (NY): National League for Nursing; 2007.

14. Martins JCA, et al. A experiência clínica simulada no ensino de enfermagem: retrospectiva histórica. Acta paul. enferm 2012; 25(4): 619-625. http://dx.doi.org/10.1590/S0103-21002012000400022

15. Miller GE. The assessment of clinical skills/competence/performance. Acad Med 1990; 65(9 suppl): S63-S67. Available from: URL: http://journals.lww.com/academicmedicine/Abstract/1990/09000/The_assessment_of_clinical.45.aspx

Recebido 28 de setembro de 2017

Aceito: 18 de fevereiro de 2018 